\title{
How medical school has changed my views of medicine
}

\author{
Timothy Rinaldi
}

Received: 24 January 2014/ Accepted: 26 February 2014/Published online: 25 March 2014

(C) Springer-Verlag Italia 2014

Growing up with a father who is an oncologist and a mother who was a nurse, I always had a strong interest in going into medicine. As an undergrad at Tulane University, I became involved in medical mission work in Honduras, the Dominican Republic, and Kenya. I witnessed Dominican and Honduran families who walked for hours to come to the clinics we were running to see a doctor for the first time in their lives. I heard a father tell his story of carrying his son with a broken arm for hours down the mountain before they finally caught a ride into the city where the nearest hospital was located. I attempted to give deworming medication to Kenyans, many of whom refused because they did not believe in western medicine. I would have done anything to help these people, but I could not as just an undergrad student. From these experiences, I knew without a doubt that I wanted to become a physician to truly have an impact on communities here at home and in developing countries.

I strove for excellence in the classroom, committed most of my free time to service, and studied harder than I ever had before for the MCAT to ensure I would get into medical school and become closer to achieving this dream. The application process was incredibly frustrating and time consuming-how could some lesser ranked schools not even want to interview me while others accepted me-but I tried to not let it get me down. Getting into the schools solidified that this was what I was meant to do, and eventually I chose to attend the Baylor College of Medicine.

Leading up to the beginning of school at Baylor in July of 2012, I was ready to work harder than ever to become

T. Rinaldi $(\bowtie)$

Baylor College of Medicine, Houston, USA

e-mail: rinaldi@bcm.edu the best physician I could be. I had never wanted something more; this motivation was going to lead to greater successes and opportunities. I finally was starting medical school and each day I would be a little closer to becoming a physician. Nothing could stop me from becoming a highly respected physician and serving many, many people both here and abroad. Growing up, I heard stories from my dad's patients about how he saved their lives and how much they loved him; I fully expected to soon have that role after finishing with medical school. It was an incredible feeling.

And then school started. I got to wear a white coat and work with physicians every other week, I had small group sessions analyzing case reports, and I got to work with a cadaver in the anatomy lab; however, I was still studying basic sciences and it was not quite as special as I expected. Why was that still necessary after taking so many similar classes during my undergraduate education? How could learning the Krebs cycle benefit my future patients? Were all of the sacrifices and hard work really worth it?

As my first year of medical school continued, the material became more medically relevant and I felt more like a future physician. It was certainly exciting, but it also left me feeling overwhelmed-how would I ever learn all of this material and know what I needed to know to help future patients? School continued at a much faster pace than I was ready for, and I learned physiology, pharmacology, immunology, infectious diseases, behavioral science, and ethics. I did well enough, but doubts began to pervade - I had always been a good leader, was determined, and very passionate about helping those in need, but was this enough? After going to Honduras eight times and leading the construction of a medical clinic in the isolated mountain villages, the people there loved me and even named children after me because of my service 
and compassion; but what good were these qualities if I did not have the knowledge necessary to treat my future patients?

After a much-needed month off for summer, I spent my final preclinical semester relearning the physiology and then the pathology of each system, along with patient safety, continuing with small groups, and working with my preceptor. With exams every 3 weeks or so, it was a flood of information without much time to regroup. We learned about the risk of physician burnout while I struggled with feeling burnt out from the course load. While I had more confidence after taking so many exams, I still was just focused on making it to clinical rotations to really start to move forward with my education. Completing the rounds of exams and the End of Basic Sciences Exam in December was a huge relief because I was finally ready to move on to clinical rotations!

Except that I am not. I will be lost on the wards; rather than saving lives, my more pressing concern is not frustrating the residents too much. The one thing that I have learned the most at medical school is how much there is to learn and how far away I am from providing medical care to those in need. And perhaps that is the most important lesson-I will never be done learning. To be the best physician I can be, I need to learn from each of my patients and always question what I know.

Yet, I am still excited to be moving into the wards this month. I will assuredly be lost, but I am legitimately closer to becoming a physician. I really cannot do much yet, but I will be working with patients in need. I may not be the one to make the diagnosis and prescribe their medications, but I can console and care for them. For almost all of my patients, their outcomes will not be affected by my presence at their bedsides. But my outcome as a physician will be affected by their presence in my life; instead of using a textbook, I will be learning disorders through the patients and their loved ones. Each day I will be closer to becoming a physician and each patient will bring me closer to becoming a great physician.

So how have my views of medicine changed during my time in medical school? Before school, I wanted to become a physician because I respected them so much for the impact they could have on those in need. I worked with people in developing countries who did not have access to physicians and saw the drastic consequences it had on them. I wanted to be the one who could provide the medical care they desperately needed. Now, I have even more respect. My most memorable lecture of school so far was with Dr. William Shearer, the renowned physician of David Vetter (the "bubble boy") in Houston more than 30 years ago. He visited our class with David's mother and sister and they spoke about David's life and Dr. Shearer's role with their family. To me, the most powerful part of the lecture was seeing the relationship between Dr. Shearer and David's mother and sister; Dr. Shearer is basically a member of their family to this day even though he was ultimately unable to save David's life. Dr. Shearer's compassion for David and his family was one of the most important lessons of my preclinical studies.

Certainly, not all physicians are altruistic and motivated by compassion. Still, countless people want to become physicians but change their minds because of the time and work necessary to achieve it. Not only are physicians doing great things, but they did not quit when the course load was boring at the beginning of school, when it seemed to be too much, when they were clueless on the wards during rotations, or when they had incredibly stressful schedules as interns and residents. Not only do physicians have to know so much to help their patients, but they also have to focus only on their patients and ignore the endless controversy over the healthcare system in the United States.

And this is what gives me hope for the future of medicine in our nation; everyone in the medical field worked too hard and is too determined to allow the system to fail. Knowing how hard we work and meeting young physicians and other medical students, I have no doubt we will thrive and our nation will once again be proud of its healthcare. Before enrolling in medical school, I had a naïve respect for physicians. Now, I am still naïve but I have a much greater understanding for the lives of those in the medical field and why they deserve our respect and admiration.

Conflict of interest I certify that there is no conflict of interest with any financial organization regarding the material discussed in the manuscript. 